\title{
RECENT DEVELOPMENTS IN THE RASCING OF BIOSTRATIGRAPHIC EVENTS
}

AGTERBERG*, Frederik P., Geological Survey of Canada, 601 Booth Street, Ottawa, K1A0E8, Canada; GRADSTEIN, Felix M., Saga Petroleum a.s., Kjørboveien 16, N-1301 Sandvika, Norway.

Traditionally, paleontologists and stratigraphers have been concerned with the first appearance datum (FAD) and last appearance datum (LAD) of one or more taxa in the stratigraphic record. These biostratigraphic events are helpful for many purposes including the construction of local, regional or global stratigraphic range charts and zonations, and their use for stratigraphic correlation. The FAD or "entry" and LAD or "exit" of a taxon can be regarded as the endpoints of two frequency distributions. This implies that the observed entry and exit of a taxon in a given section or well may be random events which provide biased estimates of the truly lowest and highest occurrence, respectively. The magnitude of this bias depends on the shapes of the frequency distributions of the entries and exits and these, in turn, depend on many factors including geographical extent of the study area.

A clear distinction should be made between the frequency distribution for occurrence of the taxon itself and the frequency distributions of the stratigraphic events derived from it. A common problem is that neither of these two types of mutually interrelated frequency distributions can be determined with precision. This paper deals with methods to estimate statistical parameters of the frequency distributions of entries and exits. The main examples of application will be exits of Cretaceous and Cenozoic Foraminifera from the North Sea Basin. The computer program RASC for ranking and scaling of biostratigraphic events was used to estimate the average positions of the exits of these taxa which, stratigraphically, occur well below their truly highest occurrences. By means of a new method of variance analysis, the standard deviations and skewness measures of the frequency distributions of the events are estimated from deviations between the observed and average positions of the events in all well sections considered. The positions of the truly highest occurrences of the taxa also can be estimated in this way. Finally this method can be useful for tracking the time transgressive behavior of events.

RASC results in an optimum sequence or scaled optimum sequence of average biostratigraphic events. For each well section the observed data can be plotted against either one of these two types of optimum sequences, and lines of correlation can be fitted in order to estimate the average positions of the events in the section. The deviations between the observed events and these lines of correlation are used for the variance analysis. Taxa with highest occurrences that are good markers are characterized by relatively small standard deviations. All estimated standard deviations can be converted into error bars along the depth scale of the well section. In general, these error bars are asymmetrical and different for the same taxon in different well sections because they reflect differences in rates of sediment accumulation. They also depend on taxon sample sizes and position along the line of correlation in a section.

Other developments in the "rascing" of biostratigraphic events include a new method of ranking (condensed optimum sequence) and flexible window scaling. The condensed optimum sequence option allows for the calculation of groups of events which are coeval on the average. Scaling with a flexible window helps to eliminate bias in the scaled optimum sequence caused by relatively small sample sizes for pairs of taxa as, for example, may occur near the top and base of a scaled optimum sequence.

The original RASC computer program was published 15 years ago. The recent developments have been implemented in a new version of RASC written in FORTRAN for personal computers. 